\title{
Wild edible fruit tree resources of Arunachal Pradesh, North East India
}

\author{
N. Lyngdoh ${ }^{*}$, Ng Piloo ${ }^{2}$, Tape Gab ${ }^{3}$, Mukul Kumar ${ }^{1}$ and A.K. Pandey ${ }^{4}$ \\ ${ }^{1}$ Department of Tree Improvement, College of Horticulture and Forestry, Central Agricultural University, Pasighat- \\ 791102 (Arunachal Pradesh), INDIA \\ ${ }^{2}$ Department of Post Harvest Management, College of Horticulture and Forestry, Central Agricultural University, \\ Pasighat-791102 (Arunachal Pradesh), INDIA \\ ${ }^{3}$ State Horticulture Research and Development Institute, Itanagar-791111 (Arunachal Pradesh), INDIA \\ ${ }^{4}$ Dean's Office, College of Horticulture and Forestry, Central Agricultural University, Pasighat-791102 (Arunachal \\ Pradesh), INDIA \\ *Corresponding author. E-mail: lyngdoh@gmail.com
}

Received: August 31, 2015; Revised received: March 12, 2016; Accepted: May 28, 2016

\begin{abstract}
The paper reports on the survey of wild edible fruit trees covering 49 sites from 17 districts of Arunachal Pradesh, India. A total of 52 wild edible fruits species representing 33 families was reported, out of which 10 had medicinal uses. The highest number of wild edible fruits belonged to family Moraceae ( $9 \mathrm{spp}$.) followed by Anacardiaceae (4 spp.) and Actinidiaceae (3 spp.). More than half the fruits (66.67\%) are available during the monsoon season, i.e. between June and October. Dilenia indica, Castanopsis indica, Canarium strictum, Terminalia citrina, Phoebe cooperiana, Phyllanthus emblica and Artocarpus intergifolia are the commonly traded fruits. This is perhaps the only extensive survey which has so far been carried out on wild edible fruit tree resources covering all the districts of Arunachal Pradesh. In the present era where there is global interest on bioresource documentation, this study is significant for securing intellectual property right and preventing biopiracy.
\end{abstract}

Keywords: Diversity, Medicinal, Traded, Underutilized, Wild fruit tree resources

\section{INTRODUCTION}

Arunachal Pradesh $\left(26^{\circ} 30^{\prime}\right.$ and $29^{\circ} 30^{\prime}$ North and $91^{\circ}$ $30^{\prime}$ and $97^{\circ} 30^{\prime}$ East) is the largest state of North East region of the country covering an rea of $83,743 \mathrm{sq} \mathrm{km}$ with $80.39 \%$ of geographical area under forest cover (Anonymous, 2013). Having an altitudinal range between 150 and $7000 \mathrm{~m}$, it is presented with diverse forest types which harbors rich floral and faunal diversity. The state is also strategically located within the Indo Myanmar biodiversity hotspot (Myers et al., 2000) making it one of the prime areas for ethnobotanical studies and bio resource explorations. Further, community diversity in the state which comprises of 26 main tribes and 110 minor/sub tribes with distinct socio-cultural settings and traditional knowhow is a store house of untapped wealth.

Wild edibles are a part of the food habits of people in many societies and intimately connected to virtually all aspects of their socio-cultural, spiritual life and health. Infact, most rural communities in India depend on the wild edible plants to meet their food needs during the food crisis, as well as for additional food supplements. It has been reported that there are 1532 edible wild food species in India, mostly from Western Ghats and Himalayan regions (Arora and Pandey, 1996). Recently wild edibles have captured the inter- est of many researchers throughout the country and especially in the eastern Himalayan region where human populations live in close association and harmony with nature. Consequently, there is growing number of records on wild edible plants reported from various states of the north east (Kayang, 2007; Jeeva, 2009; Singh et al., 2012; Gangte et al., 2013; Brahma et al., 2013; Deb et al., 2013). However, most studies provide a generalized approach of documenting wild edible plants by including all categories such as vegetables, medicines, fruits, spices, etc. in a single report or the reports were confined to a district, tribe or within a protected area. Nevertheless, these reports highlight the immense wealth of untapped biodiversity and associated traditional knowledge harboured in various parts of the region.

In the present paper we primarily aim to document the diversity, time of availability and the associated traditional uses of wild edible fruit trees species in the entire state of Arunachal Pradesh. Wild edibles fruits play a significant role in human dietary and nutrition requirement. They are known to be excellent source of nutrients such as minerals and vitamins (Nahar et al., 1990). Their importance is even more profound among forest dwellers and marginalized rural communities where conventional fruits are scarce or unaffordable. With changing market demands and under present 
climate change scenarios documentation of the edible fruit tree resources of Arunachal Pradesh, North East India is paramount. In addition, the study becomes very pertinent in the present era of securing intellectual property rights and prevention of biopiracy.

\section{MATERIALS AND METHODS}

The study areas for the investigation consisted of 49 sites in Arunachal Pradesh surveyed during 2012 to 2014. All 17 districts of Arunachal Pradesh were included in the study with each district represented between 1 and 4 sites as shown in Fig 1. Where ever possible, sites were chosen within each district in such a manner that they broadly represent different agro climatic zones. For obtaining information on wild edible fruit present in the area, a home based approach was adopted. At each site village headman/ progressive farmer/ village elder was identified and meetings were arranged. A semi structured interview was conducted to obtain information on the types and number of resources available, season of harvest, usage pattern, trade information, mode of consumption, medicinal uses and any traditional knowledge associated with the tree species. Visit to the nearby forest area of respective sites was then undertaken for sample collection. Species identification was done following the regional floras and was counter checked with the help of the herbarium of the Botanical Survey of India, Itanagar.

\section{RESULTS AND DISCUSSION}

A total of 67 wild edible fruit trees were documented which are commonly consumed by the people of Arunachal Pradesh. However, not all fruits which have been documented could be identified completely. The number of fruit identified up to species level was 52 repre-

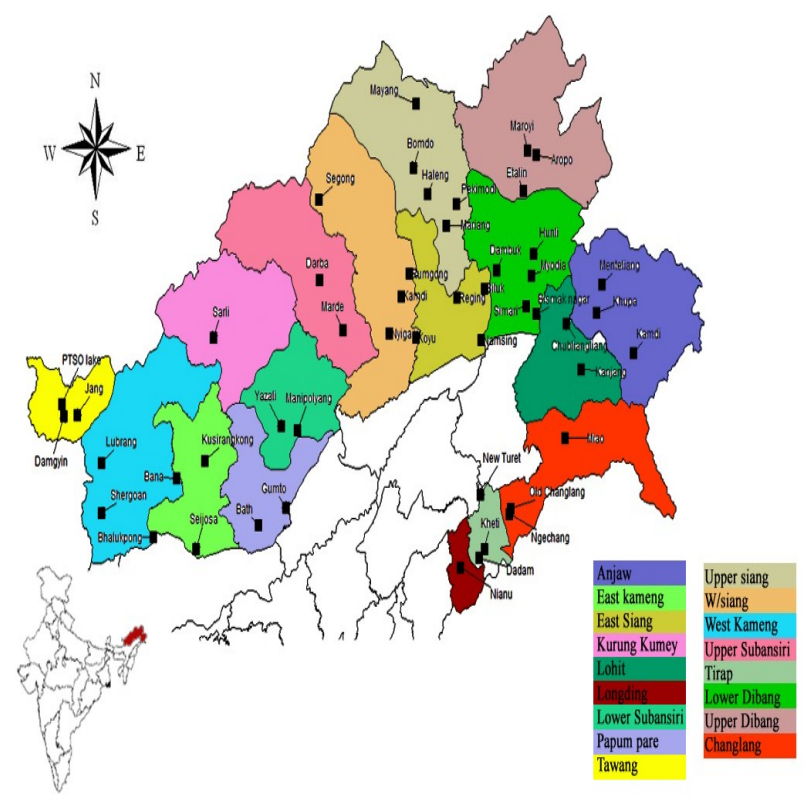

Fig. 1. Map showing the 49 sites surveyed for wild edible fruit trees in the state of Arunachal Pradesh. senting 33 families. Documentation of wild edible fruits in Arunachal Pradesh have been earlier included in broader studies on edible plants such as that of Rawat et al. (1998) and Angami et al.(2006).More recently, Yumnam et al. (2011) who restricted their survey only to East Siang district of Arunachal Pradesh, recorded 26 plant species used as edible fruits. In other parts of North East, Brahma et al. (2013) recorded total of 32 wild edible fruits belonging to 23 families that are used by Bodo tribe of Kokrajhar district of Assam while Chakraborty and Chaturvedi (2014) reported a total of 61 wild fruit plants in the state of Tripura, out of which 45 species were trees. Considering the size and topographical variation of Arunachal Pradesh, 67 fruit species as reported is less and we agree that the actual number of species should far exceed that value. In our defence, for one, the study was restricted to tree species and that many areas in the state are still inaccessible which make extensive survey a daunting task. Further the period for conducting surveys is restricted to the dry months, which makes sampling of plant sample/reproductive structures incomplete and therefore problems in identification. None the less, this report presents the most extensive survey on commonly available wild edible fruit tree species in the entire state of Arunachal Pradesh.. The list of wild edible fruit trees along with their major distribution and mode of consumption is provided in Table 1. Additional information on the distribution was also obtained from Materials or the Flora of Arunachal Pradesh, Flora of India series 2. The highest number of wild edible fruits belonged to family Moraceae ( 9 spp.), followed by Anacardiaceae (4 spp.) and Actinidiaceae (3 spp.). The families Phyllanthaceae, Burseraceae, Fagaceae, Lauraceae, Rosaceae and Combretaceae were represented by $2 \mathrm{spp}$. each and the remaining by one spp. only. Earlier, Chakraborty and Chaturvedi (2014) in their survey on wild edible fruits of Tripura reported highest representation of species from Moraceae family while Dangwal et al. (2014) reported 3 tree species of Moraceae family used as wild edible fruits in their survey at Rajouri District of Jammu and Kashmir. Out of the 52 species, 10 species were reported to be used for medicinal purposes by various tribes (Table 2), the knowledge which has been passed for generations among the local community. Among these, Averrhoea carambola, Canarium strictum, Phyllanthus emblica and Terminalia bellirica are reported to be commoly used for various ailments in other parts of the India as well (Sheth, 2005; Namsa et al., 2009; Meena et al., 2012; Bajracharya, 1979; Williamson, 2002; Amrithpal, 2011).

Fruits were mainly consumed in raw form with few also roasted such as Castanopsis hystrix, Castanopsis indica, Illicium griffithi, Litsea citrata, Michelia champaca, Phoebe cooperiana, Pyrus pashia and Sterculia hamiltonii. Fruits which were boiled include Dellinia indica, Litsea citrata and Tevesia palamata. 

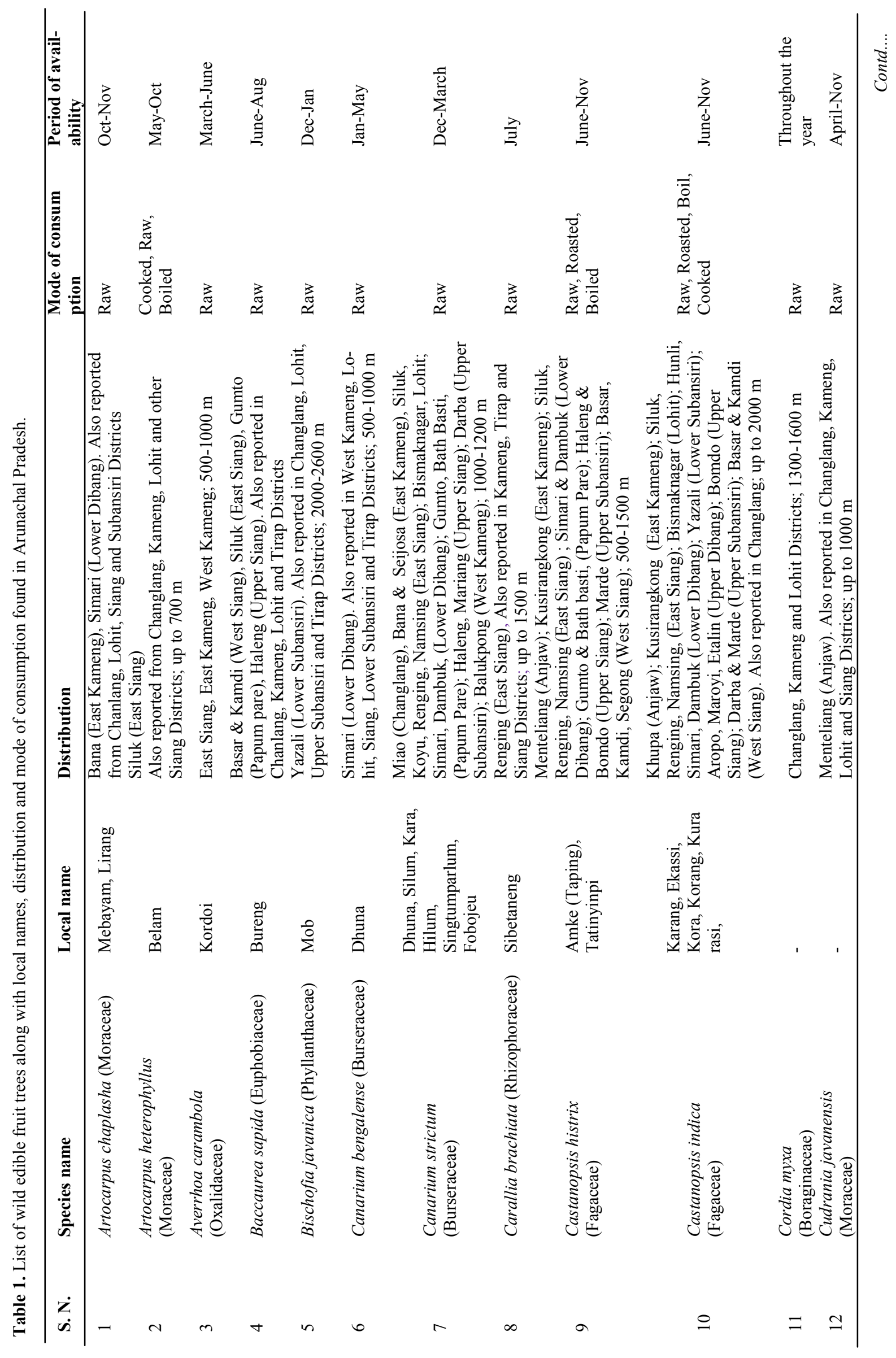


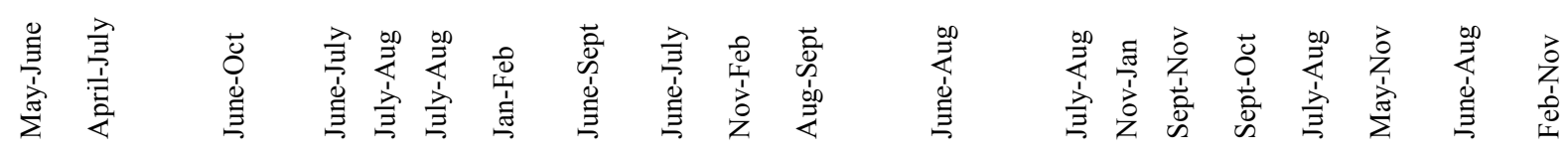

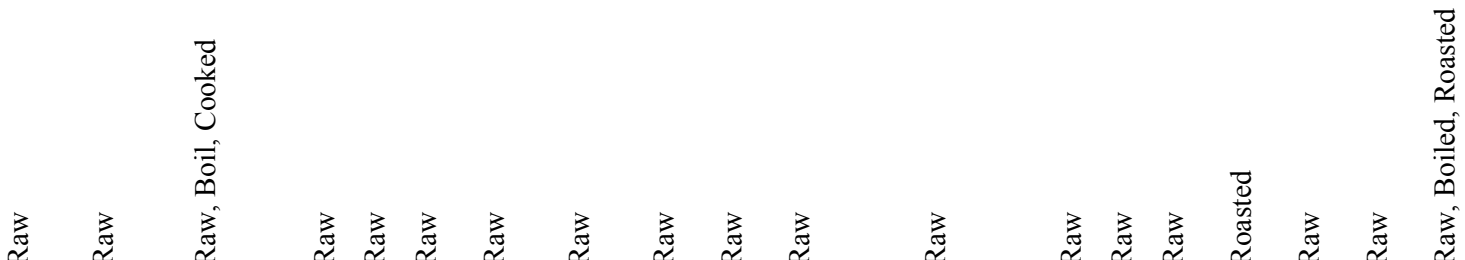

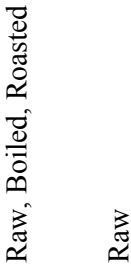

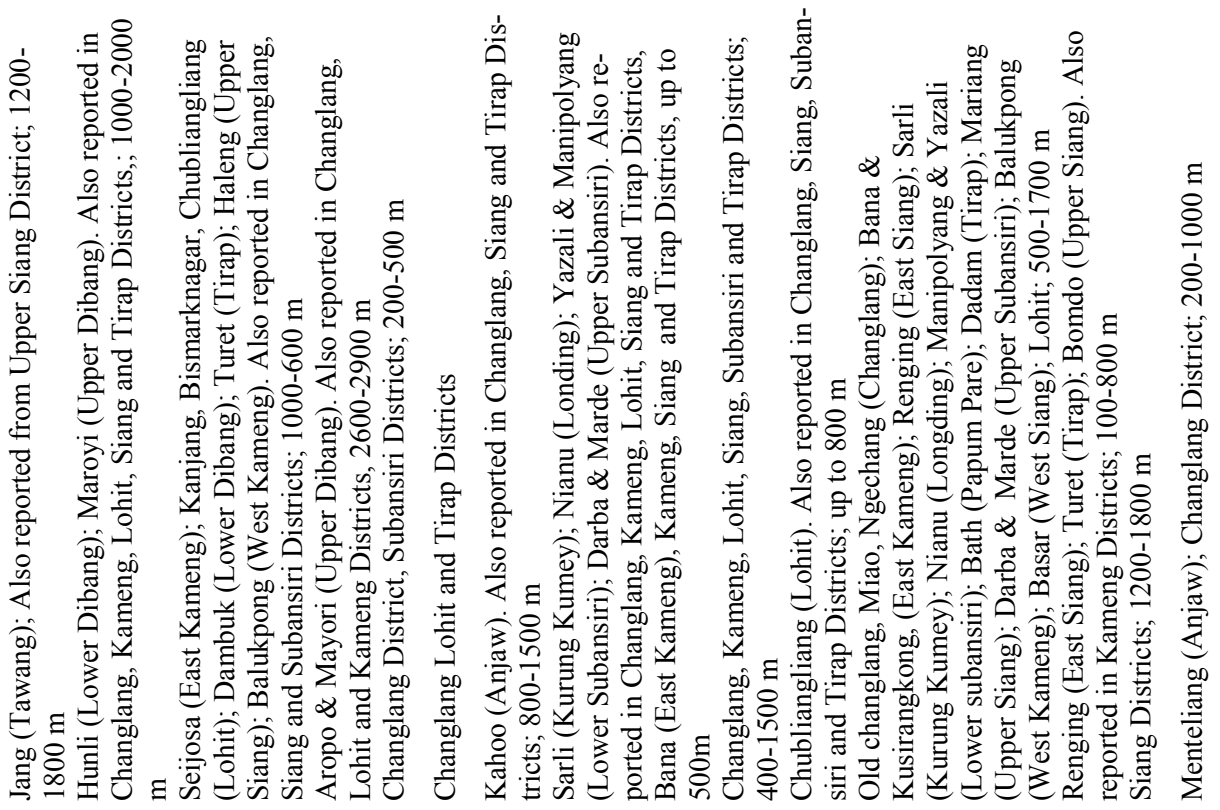

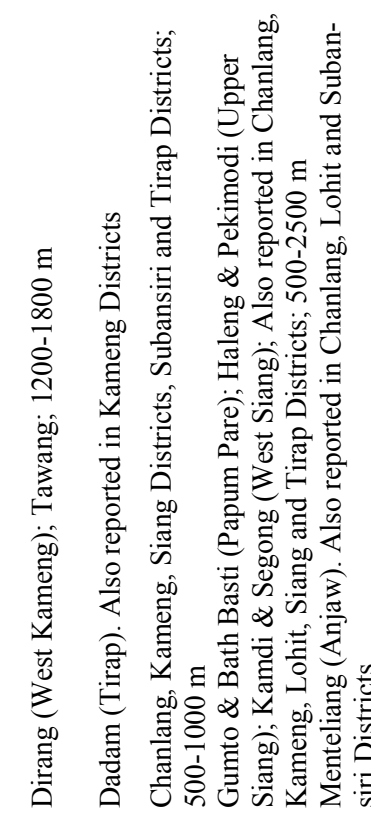

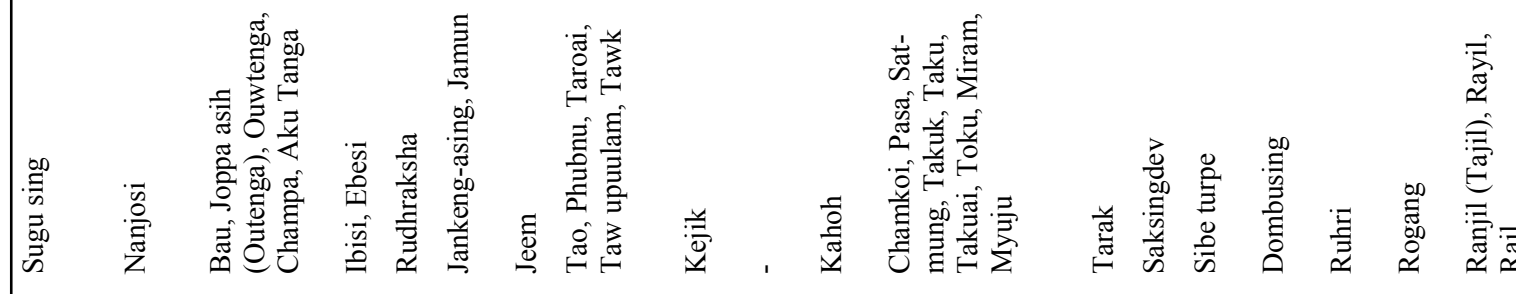
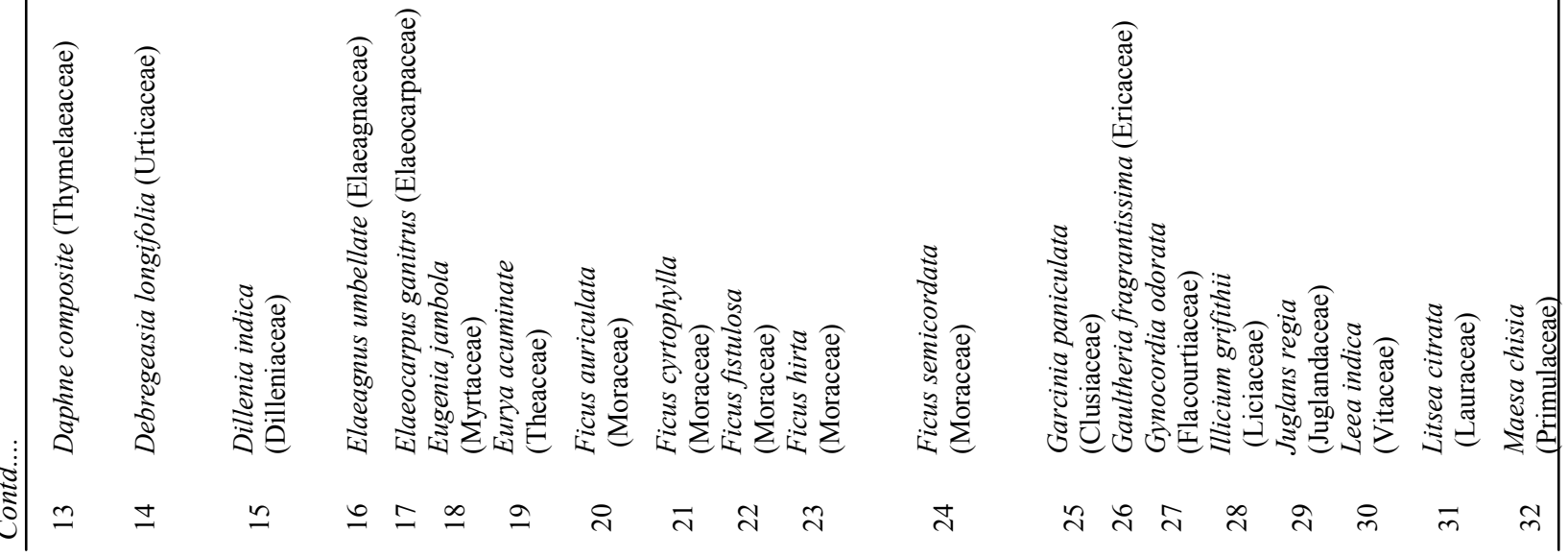


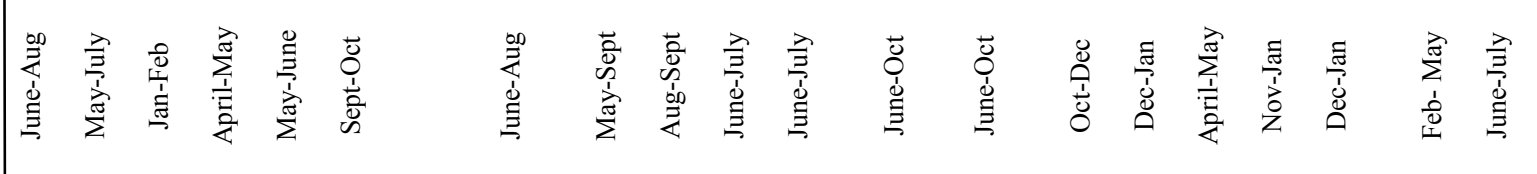

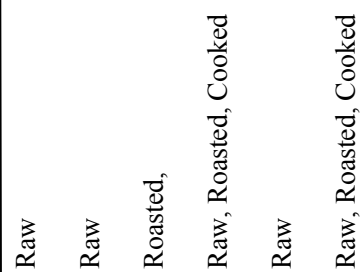

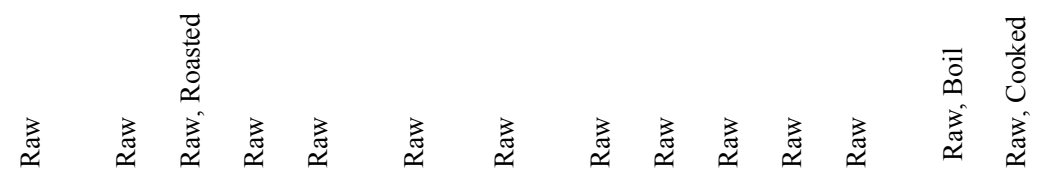

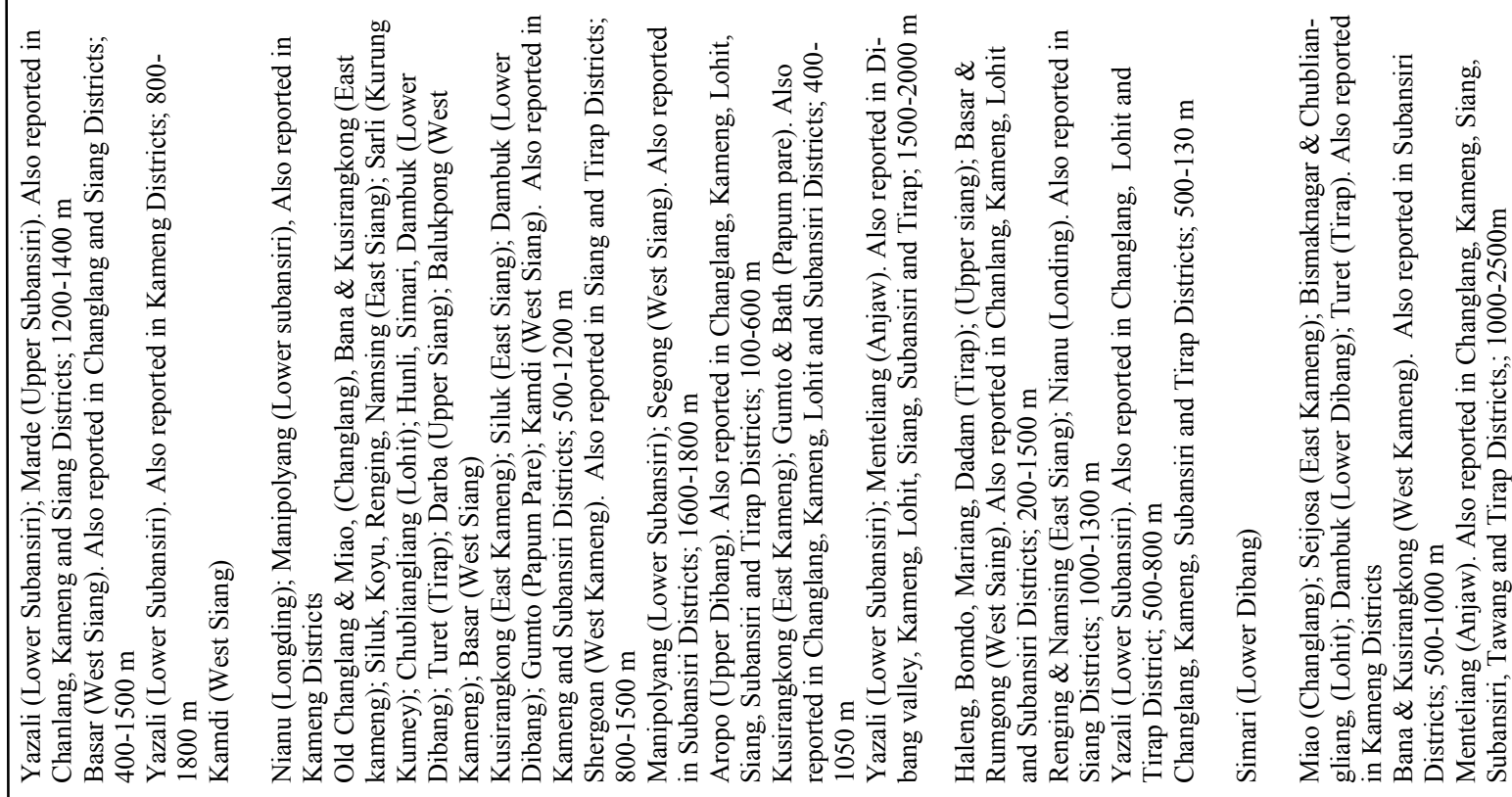

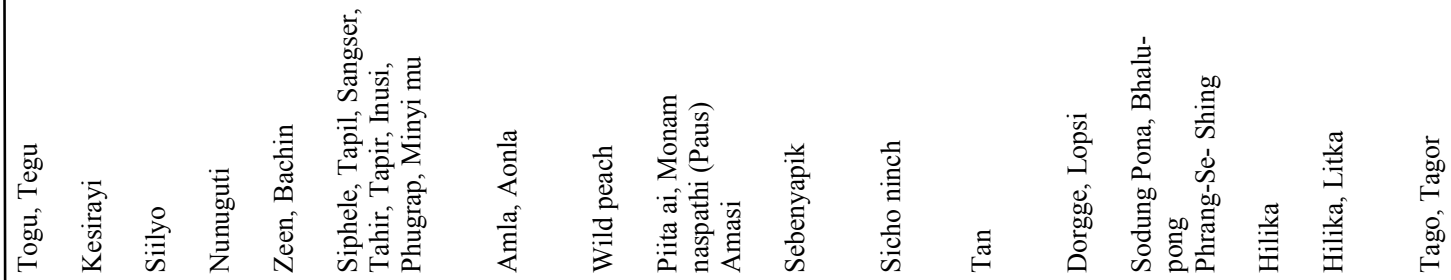
i⿱丶万仒<smiles>CC1[C@H](C)C[C@H]1C</smiles><smiles>C[C@H]1[C@H]2C[C@@H](C2)[C@@H]1C</smiles><smiles>CC1[C@H](C)C[C@H]1C</smiles>

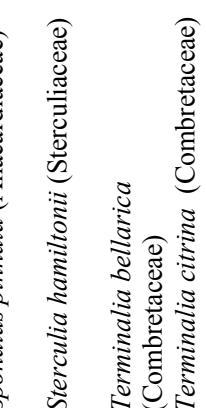


Table 2. List of wild edible fruits traditionally used as medicines in Arunachal Pradesh along with part used, purpose and method used.

\begin{tabular}{lllll}
\hline S. N. & Fruit tree name & Part used & Purpose & Method of use \\
\hline 1 & Averrhoea carambola & Fruit & Jaundice \& diarrhoea & Eating \\
2 & Canarium strictum & Fruit & Mouth freshner & Eating \\
3 & Litsea citrata & Fruit & Stomach ache \& ulcer & Grind fruit \&decoction is taken \\
4 & Mangifera sylvatica & Bark & Jaundice & Juice \\
5 & Michelia champaca & Seed & Stomach ache & Eating \\
6 & Myrica esculenta & Fruit & Scurvy \& mouth ulcer & Eating \\
7 & Phyllanthus emblica & Fruit & Digester & Decoction \\
8 & Terminalia bellarica & Fruit & Stomach ache & Eating \\
9 & Terminalia citrina & Fruit cover & Chest pain, Stomach pain \& urinary & Eating \\
10 & Zanthozyllum acanthopodium & Fruit & Stomach \& head ache & Eating \\
\hline
\end{tabular}

More than half the fruits $(66.67 \%)$ are available during the monsoon season, i.e. between June and October (Table 1). During the monsoon remote areas of Arunachal Pradesh are usually cut off due to landslides, which are sometimes for extended periods, creating huge problems for food supplies. While wild edible fruits can available during monsoon thus serve as alternatives to staple food during periods of food deficit the fruits that are available during other seasons creates an all year round availability of nutrient supplement to the local people. Trading of wild edible fruit in the state is mostly restricted to sites near district headquarters where marketing opportunities exist. Commonly marketed fruits include $D$. indica, $C$. indica, $C$. strictum, Terminalia citrina, P. cooperiana, P. emblica and Artocarpus intergifolia. . The fruits are always traded in raw form with absolutely no value addition. P. cooperiana which is consumed at all developmental stages is the most demanded wild fruit in the entire state and the cost may range between Rs.20 and Rs.30 for 4 fruits at the Itanagar, the state capital.

With rapid land transformation, growing connectivity and eroding cultural values, wild edible fruits are gradually being neglected by rural communities. During the survey, very few wild edible fruit trees were noticed around village areas and neither was planting of edible fruits trees encouraged. Local extinction of a species does not simply mean there is one fruit type less for the locals to consume but may have far reaching implications which includes ecological imbalances in the area. Therefore knowledge on the availability of wild resources and status is crucial. Further, such wild resources may have the potential to become conventional foods of the future, be used as parents in breeding programs, as convenient sources of income and as vehicles for improved nutrition and increased food supply.

\section{Conclusion}

This paper documents the diversity of wild edible fruits tree in the entire state of Arunachal Pradesh. It was observed there are 52 common wild edible fruits trees in the study area, out of which 10 were reported to be of medicinal use. The state of Arunachal Pradesh is bountiful in its resources and much more species of wild fruits are yet to be identified, some which may be endemic to this region. Nevertheless, for the first time this reports enlists the common wild edible fruit trees found in all districts of the state. In the present era where there is global interest on bioresource documentation this study is significant for securing intellectual property right and preventing biopiracy.

\section{ACKNOWLEDGEMENT}

The authors greatly acknowledge the Science and Engineering Research Board, Government of India for providing financial support (SR/FT/LS-107/2011). Authors are also thankful to the headman/elders of villages and farmers of Arunachal Pradesh for their providing information, help and support during the study period

\section{REFERENCES}

Amrithpal, S.S. (2011). Herbalism phytochemistry and Ethanopharmacology, Science Publishers.

Angami, A., Gajurel, P.R., Rethy, P., Singh, B. and Kalita, S.K. (2006). Status and potential of wild edible plants of Arunachal Pradesh. Indian Journal of Traditional Botany, 5(4): 541-550.

Anonymous (2013). State of Forest Report. Forest Survey of India, Dehra Dun.

Arora, R.K. and Pandey, A. (1996). Wild Edible Plants of India: Diversity, Conservation and Use, NBPGR, New Delhi.

Bajracharya, M.B. (1979). Ayurvedic Medicinal Plants. Kathmandu; Piyusavarsi Ausadhalaya.

Brahma, S., Narzary, H. and Basumatary, S. (2013). Wild edible fruits of Kokrajhar district of Assam, North-East India. Asian Journal of Plant Science and Research, 3 (6): 95-100.

Chakraborty, S. and Chaturvedi, H.P. (2014). Some Wild Edible Fruits of Tripura- A Survey. Indian Journal of Applied Research, 4(9): 42-47

Dangwal, L.R., Singh, T. and Singh, A. (2014). Exploration of wild edible plants used by Gujjar and Bakerwal tribes of District Rajouri (J\&K), India. Journal of Applied and Natural Science, 6 (1): 164-169

Deb, D., Sarkar, A., Deb Barma, B., Datta, B.K. and Majumdar, K. (2013). Wild edible plants and their utilization in traditional recipes of Tripura, Northeast India. Advances in Biological Research, 7(5): 203-211.

Gangte, H.E., Thoudam, N.S. and Ginzamang, T.Z. (2013). Wild edible plants used by the Zou tribe in Manipur, India. International Journal of Scientific and Research 
Publications, 3 (5): 1-8.

Jeeva, S. (2009). Horticultural potential of wild edible fruits used by the Khasi tribes of Meghalaya. Journal of Horticulture and Forestry, 1 (9):182-192.

Kayang, H. (2007). Tribal knowledge on wild edible plants of Meghalaya, Northeast India. Indian Journal of Traditional Knowledge, 8: 177-181.

Meena, D., Nagarajan B. and Jesubalan, D. (2012). Future prospects for the critically endangered medicinally important species, Canarium strictum Roxb. A Review, Int. J. Conser. Sci., 3: 231-237.

Myers, N., Mittermeier, R.A., Mittermeier, C.G., Fonseca, G.A.B. and Kent, J. (2000). Biodiversity hotspots for conservation priorities. Nature, 403: 853-858.

Nahar, N., Rahaman, S. and Mosiihuzzaman, M. (1990). Analysis of carbohydrates in seven edible fruits of Bangladesh. J. Sci. Food Agric., 5: 185-192

Namsa, N.D., Tag, H., Mandal, M., Kalita, P. and Das, A.K. (2009). An ethnobotanical study of traditional anti- inflammatory plants used by the Lohit community of Arunachal Pradesh, India, Journal of Ethnopharmaco., 125 (2): 235-245.

Rawat, M.S., Rama Shamkar and Singh, V.K. (1998). Wild edible plants of Arunachal Pradesh. B.M.E.B.R. Vol XIX: 23-33.

Sheth, K.A. (2005). The Herbs of Ayurveda. Sheth publisher,p.140.

Singh, B., Sinha, B.K., Phukan, S.J., Borthakur, S.K. and Singh, V.N. (2012).Wild edible plants used by Garo tribes of Nokrek Biosphere Reserve in Meghalaya, India. Indian Journal of Traditional Knowledge, 11 (1): 166-171.

Williamson, E.M. (2002). Major Herbs of Ayurveda, Churchill- Livingstone, London.

Yumnam, J.Y., Bhuyan, S.I., Khan, M.L. and Tripathi, O.P. (2011). Agro-diversity of East Siang-Arunachal Pradesh, Eastern Himalaya. Asian Journal of Agricultural Sciences, 3 (4): 317-326. 